\title{
Sistem Pembuatan Jaminan Tender Pada Perusahaan Jasa Pembuatan Asuransi
}

\author{
Linda Sari Dewi ${ }^{1}$, Ester Arisawati ${ }^{2}$, Erene Gernaria Sihombing ${ }^{3}$, Linda Maulida ${ }^{4}$ \\ 1,2,3STMIK Nusa Mandiri, Jl. Kramat Raya No.18 Jakarta Pusat \\ ${ }^{4}$ AMIK BSI Tangerang, Komplek BSD Sektor XIV-C11 Jl Letnan Sutopo Banten, Indonesia \\ linda.Irw@nusamandiri.ac.id, esterarisawati@yahoo.com, erene.egs@nusamandiri.ac.id, \\ linda.Ima@bsi.ac.id
}

\begin{abstract}
A loss-making service company does not yet have a website on the information of making a Tender Guarantee as a prospective principal registration medium that will use our services for the manufacture of warranties. From the system that will be made to facilitate the making of guarantee which is certificate of Bank Guarantee. The purpose of this study to produce a system of information creation and website-based registration and registration. Online information is an important part of the development of technology in the internet world. The use of website media is very profitable for many parties, for the principal or the party of the company making the loss insurance services. The design of information systems making of this guarantee is made to assist and simplify the entire process of making the existing collateral in the company.
\end{abstract}

Keyword : services, guarantee, insurance, PHP, MySql

\section{Abstraksi}

Perusahaan jasa pembuatan asuransi kerugian belum memiliki website tentang informasi pembuatan Jaminan tender sebagai media registrasi calon principal yang akan menggunakan jasa kami untuk pembuatan jaminan. Sistem yang dibuat untuk mempermudah melakukan pembuatan jaminan yang bersifat sertifikat Bank Garansi. Tujuannya untuk menghasilkan system informasi pembuatan jaminan dan registrasi berbasis website. Informasi secara online bagian dari perkembangan teknologi dalam dunia internet. Pemakaian media website sangat menguntungkan banyak pihak, bagi principal maupun pihak dari perusahaan jasa pembuatan asuransi kerugian. Perancangan sistem informasi pembuatan jaminan ini untuk membantu seluruh proses pembuatan jaminan yang ada pada perusahaan.

Kata Kunci: Jasa, Jaminan, Asuransi, PHP, MySql

\section{PENDAHULUAN}

Indonesia sebagai negara berkembang saat ini terus berupaya untuk membangun negara baik dari segi fisik maupun non fisik. Pembangunan fisik mencakup pembangunan konstruksi dan non fisik mencakup pengadaan barang. Setiap tahunnya negara pasti mengeluarkan anggaran untuk mengalokasikan dana APBN atau APBD (Anggaran Pendapatan Belanja Negara atau Daerah) untuk mewujudkan pembangunan baik di ibukota maupun di daerah. Dana pembangunan yang telah dianggarkan tentu harus dipergunakan sebaik-baiknya demi kepentingan masyarakat umum. Demi 
keamanan dana pembangunan proyek negara maka pemerintah membuat suatu peraturan yang mengatur tata cara mekanisme proyek mulai dari jaminan penawaran, jaminan pelaksanaan hingga berakhirnya proyek.

Perusahaan jasa pembuatan asuransi kerugian yang memberikan jasa perantara dalam penanganan penyelesaian ganti rugi asuransi dengan bertindak untuk kepentingan tertanggung, mewakili kepentingan tertanggung atau client terkait kepentingan asuransi, untuk mengindefikasi kebutuhan asuransi tertanggung serta membuat polis asuransi sesuai kebutuhan. Menetapkan risiko, memonitor penerbitan polis, memeriksa kebenaran isi polis dan administrasi polis guna memberikan sosialisasi isi polis, konsultasi perasuransian dan menanggani penyelesaian klaim jika terjadi wanprestasi agar dapat diselesaikan antara penanggung dan tertanggung secara musyawarah mufakat.

Pemerintah telah memperkenalkan suatu jenis jaminan yang harus dimiliki kontraktor atau principal (pemerintah maupun swasta) sebagai syarat perjanjian antara kontraktor dengan perusahaan penjamin asuransi demi berjalannya suatu pekerjaan. Perusahaan jasa jaminan kerugian selaku mitra bisnis dari perusahaan asuransi berkewajiban untuk menyeleksi perusahaan kontraktor layak atau tidak layaknya dalam hal pembuatan jaminan yang dipergunakan untuk suatu proyek atau pekerjaan yang dilaksanakan untuk pembangunan yang dikerjakan di ibukota atau di daerah.

Hasil penelitian yang mengetahui persepsi masyarakat industri konstruksi (kontraktor) dalam menggunakan asuransi untuk menangani resiko pada proyek konstruksi, maka perlu dilakukan suatu penelitian. Tujuan dari penelitian ini adalah untuk mengetahui proyek apa saja yang biasa diasuransikan oleh kontraktor, resiko yang paling banyak timbul di proyek sehingga perlu dimasukkan dalam cakupan resiko asuransi dan seberapa besar pemahaman kontraktor akan pentingnya asuransi pada proyek konstruksi[1][2].

\section{METODOLOGI PENELITIAN}

\subsection{Konsep Dasar Sistem Informasi}

Terdapat dua kelompok pendekatan di dalam mendefinisikan sistem, yaitu yang menekankan pada prosedurnya dan yang menekankan pada komponen atau elemennya.Suatu sistem adalah suatu jaringan kerja dari prosedur-prosedur yang saling berhubungan, berkumpul bersama-sama untuk melakukan suatu kegiatan atau untuk menyelesaikan suatu sasaran yang tertentu[2].

Dalam rekayasa perangkat lunak, terdapat suatu pendekatan yang disebut Waterfall model.Nama model ini sebenarnya adalah "Linear Sequential Model". Model ini sering disebut dengan "classic life cycle" atau model waterfall. Model ini adalah model yang muncul pertama kali yaitu sekitar tahun 1970 sehingga sering dianggap kuno, tetapi merupakan model yang paling banyak dipakai didalam Software Engineering[3]. Tahap-tahap pengembangan metode Waterfall dapat dilihat dibawah ini: 


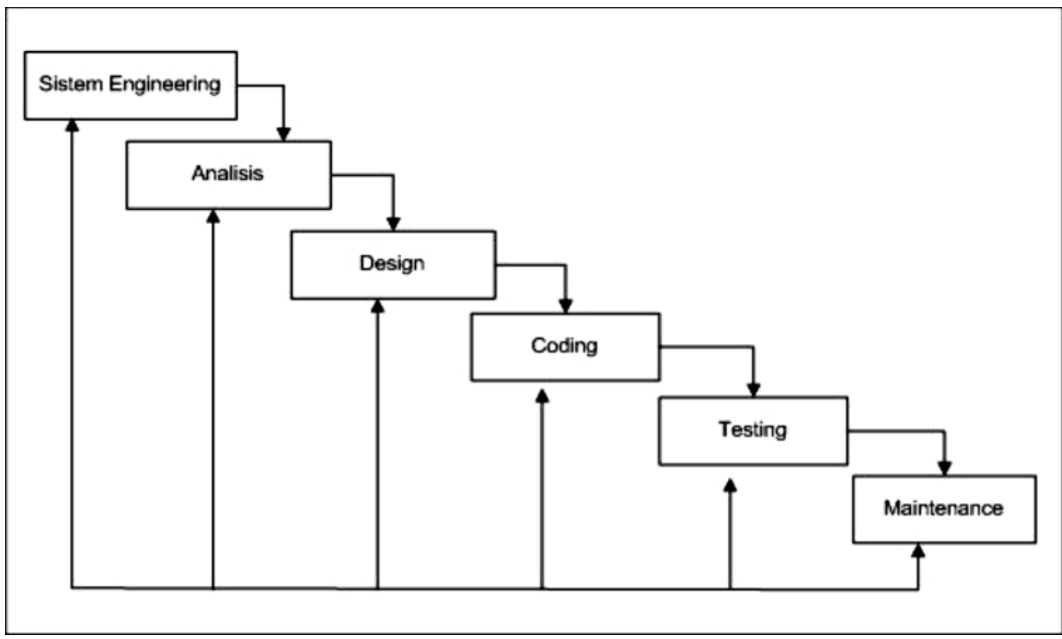

Gambar 1. Waterfall Model

Dibawah ini akan diuraikan tahap-tahap pengembangan perangkat lunak dengan menggunakan metode Waterfall, yaitu [3]:

a. System Engineering

Tahap rekayasa sistem, pada tahap ini yaitu menentukan kebutuhankebutuhan pada sistem yang akan dibangun. Contohnya seperti tempat penyimpanan data.

b. Analysis

Mengumpulkan kebutuhan data perbandingan dan perkembangan teknologi webservice dan web application secara lengkap kemudian dianalisa kelayakannya untuk dijadikan metode dalam pengembangan sistem informasi perpustakaanbeserta kebutuhan database yang harus dipenuhi oleh program yang akan dibuat.Fase ini dikerjakan agar menghasilkan desain sistem yang lengkap.

c. Design

Desain software memiliki berbagai tahapan yang berfokus pada atribut programyang jelas yaitu : data structure, software architecture, interface representations, dan detail procedur (algorithm). Proses desain menterjemahkan kebutuhan pengguna dalam sebuah dokumen aplikasi yang dapat diperkirakan kualitasnya sebelum proses coding dimulai. Pada tahap ini menggunakan model Unified Modelling Language sebagai perangkat pembuatan desain software.

d. Coding

Tahap Coding adalah tahap dimana hasil desain software diterjemahkan ke dalambahasa yang dapat dimengerti oleh komputer. Bahasa pemrograman PHP digunakan karena bahasa pemrograman ini mendukung aplikasi berbasis web. Database yang dihasilkan disimpan dalam aplikasi database MySQL.

e. Testing

Pengujian sistem menggunakan Black box testing, yang menganggap aplikasi sebagai sebuah kotak hitam dimana user mengabaikan sistem bisnis 
yang diadopsinya. Blackbox testing menitikberatkan pada kesesuaian suatu komponen terhadap spesifikasi.

\section{f. Maintenance}

Perangkat lunak yang telah dibuat dan dapat mengalami perbaikan sesuai dengan permintaan pemakai. Pemeliharaan dapat dilakukan jika ada permintaan tambahan fungsi sesuai dengan keinginan pemakai maupun perangkat keras.

\section{HASIL DAN PEMBAHASAN}

Diagram use case menggambarkan fungsi tertentu dalam suatu sistem berupa komponen, kejadian atau kelas atau sebagai urutan langkah-langkah yang secara tindakan saling terkait (skenario). Baik terotomatisasi maupun secara manual, untuk melengkapi satu tugas bisnis tunggal[4][5].

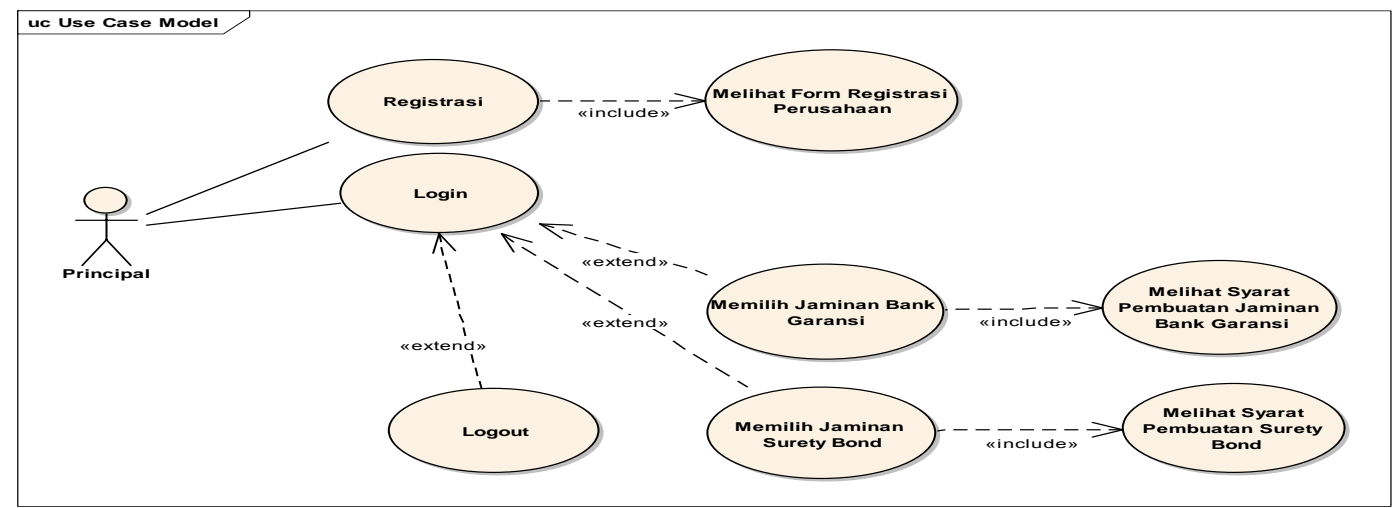

Gambar 2. Use CaseDiagram Registrasi Principal

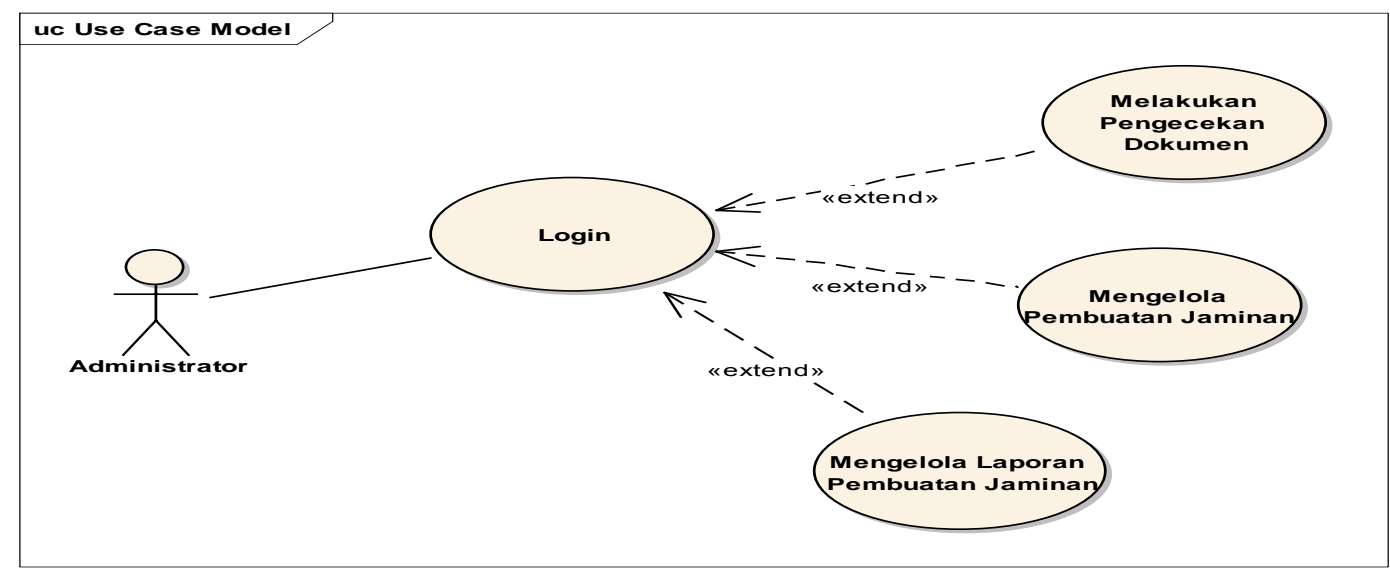

Gambar 3. Use caseDiagram Registrasi Administrator

Diagram aktivitas menunjukan aktivitas sistem dalam bentuk kumpulan aksi-aksi. Pada waktu digunakan dalam pemodelan software, diagram aktivitas mempresentasikan pemanggilan suatu fungsi tertentu [4]. 
Berikut hasil perancangan diagram aktivitas Registrasi Principal :

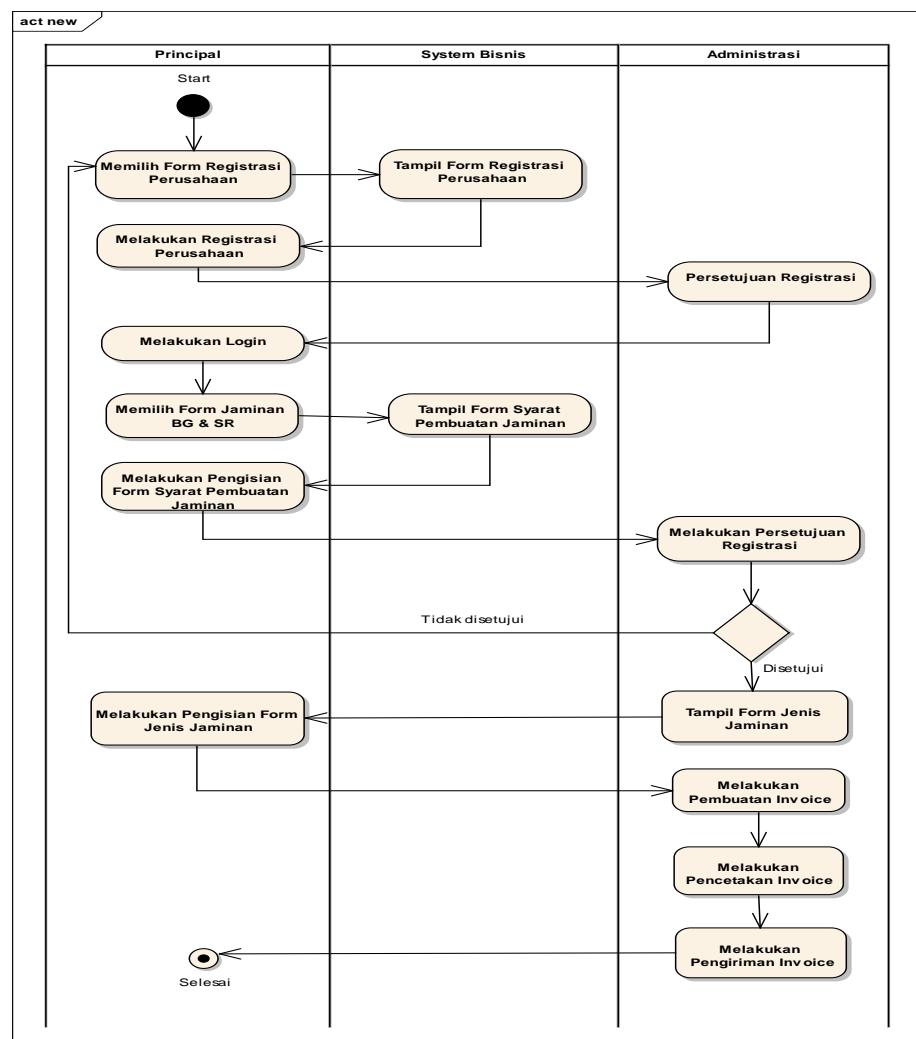

Gambar 4. Activity DiagramRegistrasi Principal

Berikut hasil perancangan diagram admin untuk pengecekan dokumen :

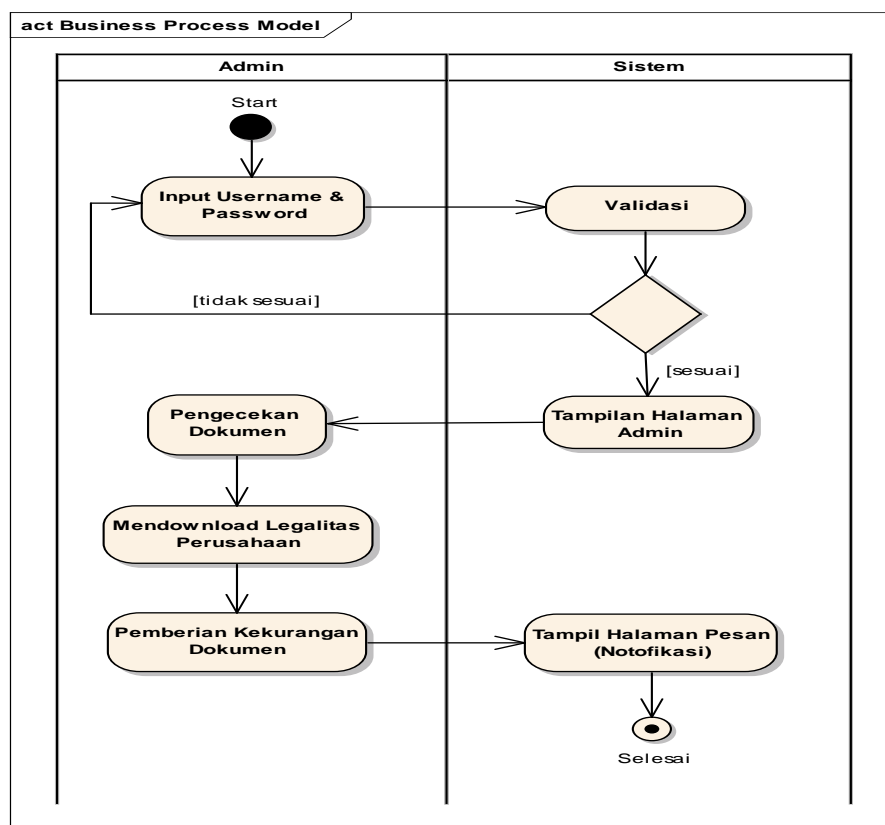

Gambar 5. Activity Diagram Admin Pengecekan Dokumen 
Jurnal Sains Komputer \& Informatika (J-SAKTI)

Volume (2) No.1 Maret 2018, pp. 76-82

ISSN:2548-9771/EISSN:2549-7200

http://tunasbangsa.ac.id/ejurnal/index.php/jsakti

Berikut hasil perancangan diagram aktivitas mengelola pembuatan jaminan :

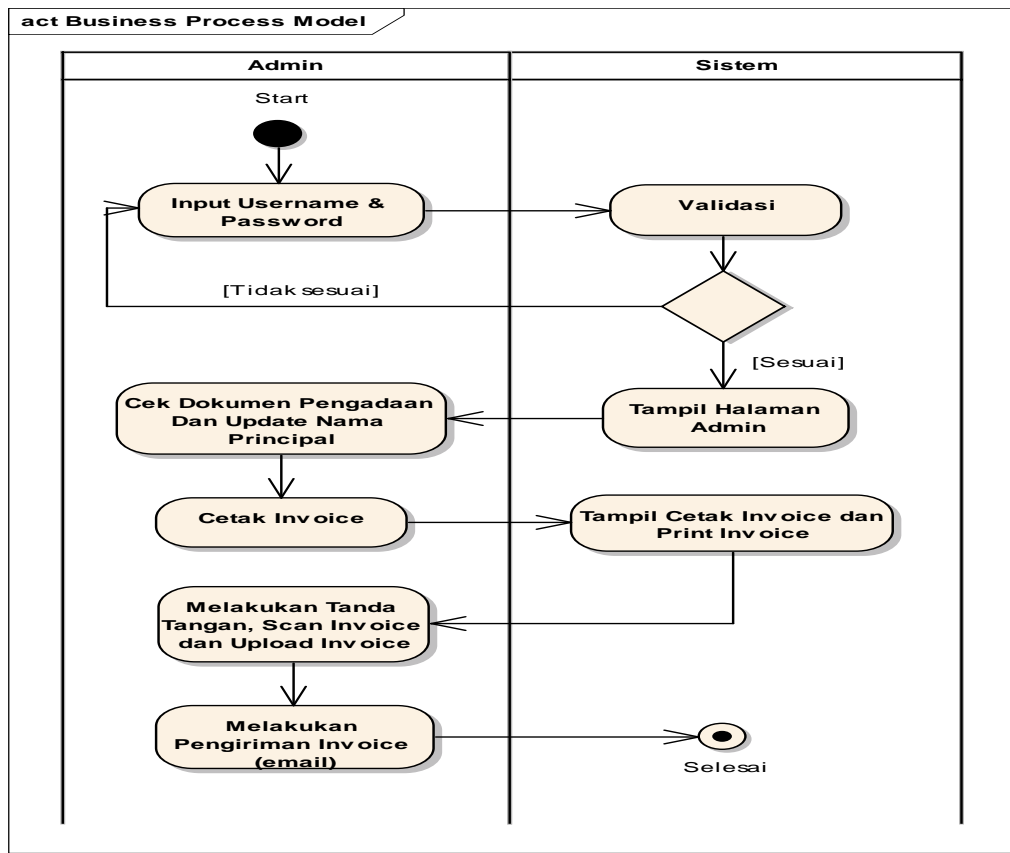

Gambar 6. Activity Diagram Admin Mengelola Pembuatan Jaminan

Berikut hasil perancangan diagram aktivitas Laporan pembuatan jaminan :

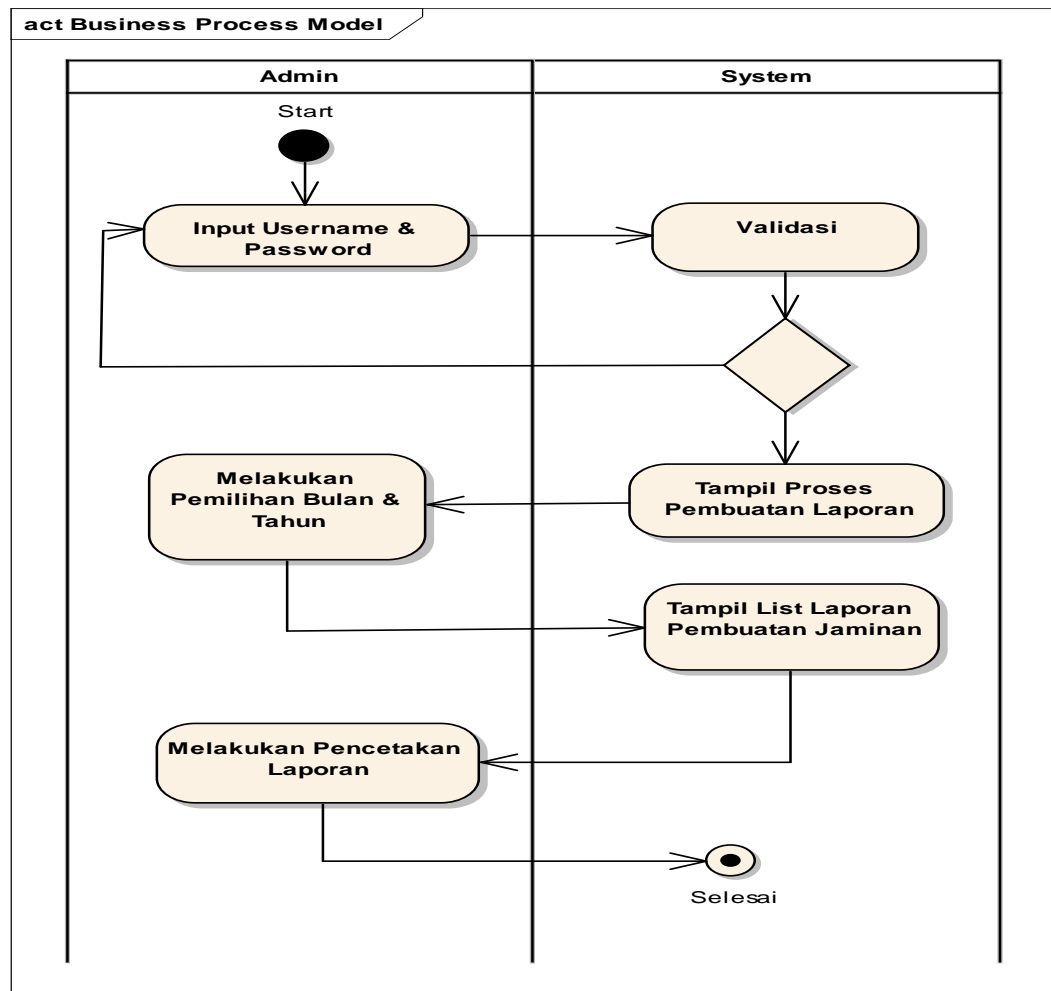

Gambar 7. Activity Diagram Admin Mengelola Laporan Pembuatan Jaminan 


\section{KESIMPULAN}

Pembuatan Aplikasi website ini dapat membantu menyelesaikan masalah yang ada pada perusahaan untuk pembuatan jaminan tender yang saat ini akan dapat dilakukan secara online serta menyimpan dan menampilkan syarat-syarat pembuatan jaminan yang dimasukan oleh pengguna secara online,daftar perusahaan yang layak untuk digunakan sebagai jaminan tender dan laporan pendapatan.

\section{DAFTAR PUSTAKA}

[1] Hartono, Jogiyanto. 2005. Analisa dan Desain. Yogyakarta: Andi.

[2] Irawan, dkk. 2012. Apresiasi Kontraktor Dalam Penggunaan Asuransi Pada Pembangunan Konstruksi Di Malang, ISSN: 1411-0660, Maret 2012. Diambil dari

http://scholar.google.co.id/scholar?hl=id\&q=apresiasi+kontraktor $+\mathrm{d}$ alam+penggunaan+asuransi+pada+pembangunan+konstruksi+di+mal ang\&btnG=

[3] Pressman, Roger S. 2005. Rekayasa Perangkat Lunak: PendekatanPraktisi / Roger S. Pressman; Diterjemahkan oleh: LNHarnaningrum. Yogyakarta: Andi.

[4] Widodo, Prabowo Pudjo dan Herlawati. 2011. Menggunakan UML. Bandung: Informatika

[5] T. Imandasari, and A. P. Windarto, "Sistem Pendukung Keputusan dalam Merekomendasikan Unit Terbaik di PDAM Tirta Lihou Kabupaten Simalungun Menggunakan Metode Promethee," Jurnal Teknologi dan Sistem Komputer, vol. 5, no. 4, pp. 159-165, Okt. 2017. doi: 10.14710/jtsiskom.5.4.2017.159-165, [Online] 